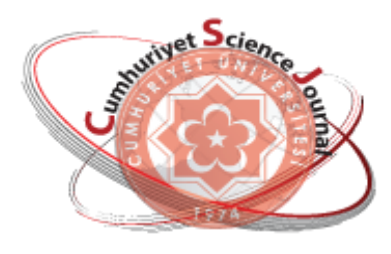

e-ISSN: $2587-246 X$

ISSN: $2587-2680$

\section{Cumanoriyot Science Journal}

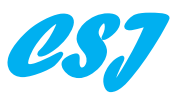

Cumhuriyet Sci. J., Vol.39-3(2018) 642-649

\title{
The Effects of Repulsive and Attractive Interactions on Step Bunching Formed on Stepped Surfaces
}

\author{
Ahmet Türker TÜZEMEN \\ Cumhuriyet University, Faculty of Education, Department of Mathematics and Science Education, Sivas, TURKEY

\begin{abstract}
A surface which consists concentric circular monoatomic steps in two dimensions and below its roughening temperature is discussed. Repulsive and attractive interactions between steps on the surface are considered. It is supposed that repulsive and attractive interactions vary as $r^{-2}$ and $r^{-1}$ respectively. Here $r$ indicates the terrace width between monoatomic steps. The solution of diffusion equation is achieved in twodimension by using polar coordinates. While the initial surface evolves, it is supposed that the local mass transfer exists because of the surface diffusion only under the step-flow model. In the study initial surfaces bounded by envelope functions which have the form of $x^{\alpha}$ are dealt. In the case of only repulsive interaction between steps surfaces evolve properly. When both repulsive and attractive interactions between steps are accepted step bunchings separated by large flat terraces occur on the surface. While the surface morphology and the evolution of the height of surface in time are investigated for all surface structures in Diffusion-Limited (DL) regime, a parameter space of bunching and no bunching regions is derived.
\end{abstract}

Keywords: Surface morphology, diffusion, repulsive and attractive interactions, step, bunching.

\section{İtici ve Çekici Etkileşimlerin Basamaklı Yüzeyler Üzerinde Oluşan Basamak Gruplaşmaları Üzerindeki Etkileri}

\begin{abstract}
Özet. İki boyutta eş merkezli dairesel monoatomik basamaklardan oluşan pürüzlülük sıcaklığı altında olan bir yüzey tartışılmışırı. Yüzey üzerindeki basamaklar arasında çekici ve itici etkileşimlerin olduğu varsayılmıştır. Çekici ve itici etkileşimlerin sırasıyla $r^{-2}$ ve $r^{-1}$ şeklinde değiştikleri düşünülmüştür. Buradaki $r$ monoatomik basamaklar arasındaki teras genişliğini göstermektedir. Difüzyon denkleminin çözümü kutupsal koordinatlar kullanılarak iki boyutta elde edilmiştir. İlk yüzey gelişirken, yerel kütle transferinin sadece yüzey difüzyonu nedeniyle basamak akış modeli altında gerçekleştiği farz edilmiştir. Çalışma içerisinde $x^{\alpha}$ biçimine sahip zarf fonksiyonları ile sınırlandırılan ilk yüzeyler ele alınmıştır. Basamaklar arasında sadece çekici etkileşimin olduğu durumda yüzeyler düzgün şekilde gelişmiştir. Basamaklar arasında çekici ve itici etkileşimlerin her ikisinin olduğu kabul edildiği zaman yüzey üzerinde geniş düz teraslarla ayrılan basamak gruplaşmaları oluşmuştur. Difüzyon sınırlı düzende (DL) bütün yüzey yapıları için, zaman içerisindeki yüzey morfolojisi ve yüzey yükseklik gelişimi incelenirken, basamak gruplaşmasının olduğu ve basamak gruplaşmasının olmadığı bölgelere ait bir parametre uzayı elde edilmiştir.
\end{abstract}

Anahtar Kelimeler: Yüzey morfolojisi, difüzyon, çekici ve itici etkileşimler, basamak, gruplaşma. 


\section{INTRODUCTION}

The evolutions of stepped crystal surfaces to their final equilibrium shapes and their equilibrium properties are important for technology at the present day. Steps occurred on crystal surfaces have a major role in crystal growth. Having knowledge about the surface morphology is a significant fact in the cases like epitaxial growth, chemical etching and catalysis. The processes such as crystal growths and reaching the equilibrium shapes of crystal surfaces happen just by the steps' motion on the surface for a surface which has steps separated by terraces. Steps' motion occurs by the attachment/detachment to/from the edges of the step of particles. The knowledge of interactions' shapes between steps on the surface is necessary to define the motion of monoatomic steps in detail. The first scientists studied on the steps' motion on crystal surface were Burton, Cabrera and Frank [1]. They dealt a surface which contains monoatomic steps separated by terraces in their study. A surface including of concentrical monoatomic steps which have circular shapes separated by terraces is studied widely [2-9]. The equilibration of a regular cone structure was studied by considering the repulsive interactions between steps in the Diffusion Limited (DL) and AttachmentDetachment Limited (ADL) regimes by Israeli and Kandel [4, 5]. Besides Ichimiya et al.[7] had experimental studies on the evolutions of the heights of silicon mounds in DL case. The repulsive interactions which vary as $r^{-2}$ where $r$ is the average step separation between steps on a vicinal surface may arise from elastic [10-12] or entropic [13] interactions. Experimental researches about the equilibration of crystal surfaces indicated that besides the repulsive interactions there must be attractive interactions between steps which vary $r^{-1}$ [14-16]. Another experimental study by Ibach et. al.[17] demonstrated the necessity of the attractive interactions between steps to estimate for the equilibrium shape. In their study Sudoh et. al.[18] have presented an argument about the source of the attractive interactions between steps. The morphologies of vicinal surfaces where the interactions between steps are repulsive and attractive at long and short separations respectively has been searched by Shenoy et. al.[19]. The existence of attractive interactions between steps has been recognized in the study of Kossel [20] and Stranski [21]. Moreover Ozdemir [22, 23] studied on the morphologies of crystalline surfaces which consist parallel steps separated by terraces by considering attractive and repulsive interactions between steps.

\section{THEORY}

In this study, we discuss a surface which consists concentric circular steps which have monoatomic height. There are flat terraces between steps which has radius $r_{i}(t)$ ( Figure 1 ). The $i^{\text {th }}$ terrace is restricted by steps $i$ and $i+1$. The surface's evolution happens through the steps' motion by attachment/detachment of particles to/from step edges.

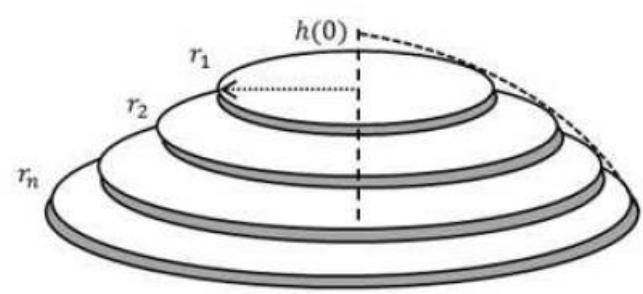

Figure 1. An initial surface which consists of monoatomic circular steps of radius $r_{i}$ separated by terraces and $h(0)$ is the initial height of the surface.

For atom concentration on $i^{\text {th }}$ terrace, the diffusion equation can be expressed as in the case of no flux to the surface,

$D_{S} \nabla^{2} C_{i}(\vec{r})=\frac{\partial C_{i}(\vec{r})}{\partial t}$

where $D_{s}$ indicates the surface diffusion constant and there is no particle desorption from the surface. The diffusion equation in polar coordinates in the case of steady state turns [5]

$\frac{\partial^{2} C_{i}(\vec{r})}{\partial r^{2}}+\frac{1}{r} \frac{\partial C_{i}(\vec{r})}{\partial r}=0$

The general solution of the equation is written as 


$$
C_{i}(\vec{r})=A_{i} \ln r+B_{i}
$$

$A_{i}$ and $B_{i}$ are arbitrary constants which can be identified by using suitable boundary conditions defined at the step edges. Boundary conditions for the $i^{\text {th }}$ terrace can be expressed as follows by presuming first order kinetics

$$
\begin{gathered}
\left.D_{S} \frac{\partial C_{i}(\vec{r})}{\partial r}\right|_{r_{i}}=k\left[\left.C_{i}\right|_{r_{i}}-C_{i}^{e q}\right] \\
-\left.D_{S} \frac{\partial C_{i}(\vec{r})}{\partial r}\right|_{r_{i+1}}=k\left[\left.C_{i}\right|_{r_{i+1}}-C_{i+1}^{e q}\right]
\end{gathered}
$$

$k$ and $C_{i}^{e q}$ represent the attachment-detachment coefficient and the equilibrium concentration of atoms on the terrace which contiguous to the $i^{\text {th }}$ step respectively. $k$ values for up and down-steps are supposed to be the identical. The equations of motion related to each step can be written by using boundary conditions in equation (4). These equations are obtained in Ref.[24] by taking into account repulsive interaction between steps only. In this study, besides repulsive step-step interaction of the form $[5,25,26]$ it is suggested an attractive interaction expression. This attractive interaction energy varies as $r^{-1}$ between $i^{t h}$ and $(i+1)^{t h}$ steps of the following form

$$
\mathrm{U}^{\prime}\left(r_{i}, r_{i+1}\right)=-\frac{G^{\prime} \sqrt{\Omega} r_{i+1}}{\left(r_{i}+r_{i+1}\right)\left(r_{i+1}-r_{i}\right)}
$$

Using the equations of motion written in dimensionless form is more suitable [5]. Supposing the distances between steps are smaller than the radii of steps and by using references [5, 25, 26] and dimensionless radii defined in [5] the chemical potential of the step can be nearly written as follows

$$
\begin{aligned}
\mu_{i}^{\prime}=\frac{1}{\rho_{i}}+g\left[\frac{2 \rho_{i+1}}{\left(\rho_{i}+\rho_{i+1}\right)\left(\rho_{i+1}-\rho_{i}\right)^{3}}\right. \\
-\frac{2 \rho_{i-1}}{\left(\rho_{i}+\rho_{i-1}\right)\left(\rho_{i}-\rho_{i-1}\right)^{3}}
\end{aligned}
$$

$\left.-g^{\prime}\left(\frac{\rho_{i+1}}{\left(\rho_{i}+\rho_{i+1}\right)\left(\rho_{i+1}-\rho_{i}\right)^{2}}-\frac{\rho_{i-1}}{\left(\rho_{i}+\rho_{i-1}\right)\left(\rho_{i}-\rho_{i-1}\right)^{2}}\right)\right]$

Here $\quad g=\left(T^{2} G\right) /\left(\Omega^{2} \Gamma^{3}\right) \quad$ and $\quad g^{\prime}$ equals $(\Omega \Gamma / T)\left(G^{\prime} / G\right) . \quad g$ and $g^{\prime}$ are dimensionless. $G^{\prime}$ and $G$ are the step-step attractive and repulsive interaction strengths respectively and $\Gamma$ represents the step line tension. The velocity of any step can be written by using dimensionless radius and dimensionless time as

$\dot{\rho}_{i}=\frac{d \rho_{i}}{d \tau}=\frac{a_{i}-a_{i-1}}{\rho_{i}}$

" $a_{i}$ " coefficient in the expression above is

$a_{i}=\frac{\mu_{i}^{\prime}-\mu_{i+1}^{\prime}}{(1-q) \ln \frac{\rho_{i}}{\rho_{i+1}}-q\left(\frac{1}{\rho_{i}}+\frac{1}{\rho_{i+1}}\right)}$

$a_{i}$ depends on 3 parameters, the first one is $q=\left[1+k \Omega \Gamma / D_{s} T\right]^{-1}$. It defines the rate-limiting processes of the surface's evolution. When $q=0$ then the surface's evolution occurs in DiffusionLimited (DL). The evolution of the surface occurs in Attachment-Detachment Limited (ADL) regime in the case of $q=1$. While $g$ measures the stepstep repulsive interaction strength $G$ relative to the line tension $\Gamma$ and $g^{\prime}$ measures the step-step attractive interaction strength $G^{\prime}$ relative to stepstep repulsive interaction strength $G$.

\section{RESULTS AND DISCUSSION}

In the study, an initial surface which has an edge structure coincides with an envelope function of the form $y(x)=h_{0}-k x^{\alpha}$ ( $\alpha$ will be taken as less or greater than 1) are discussed. $h_{0}$ shows the surface's initial height and $k$ is a constant. The surface morphologies and the evolutions of the heights of dealt surfaces are analyzed in Diffusion Limited regime $(q=0)$, when there is only repulsive interaction between steps $\left(g^{\prime}=0\right)$ and when there are attractive and repulsive interactions between steps $\left(g^{\prime}=1\right)$ on the surface. The initial surfaces which we considered are given in Figure 2 for $\alpha=\frac{1}{3}, \frac{1}{2}, 2,3$. 


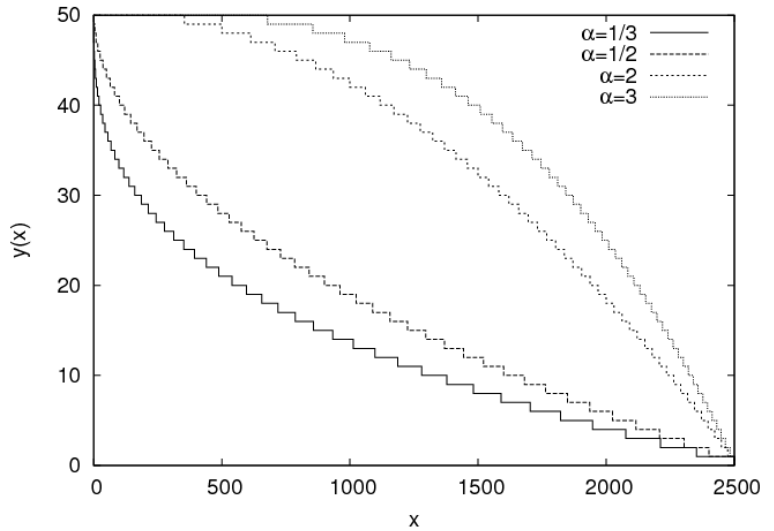

Figure 2. The side views of initial surfaces which we considered of the form $y(x)=h_{0}-k x^{\alpha} . h(0)$ is the surface's initial height. $\alpha$ values are taken as $\frac{1}{3}, \frac{1}{2}, 2,3$ in this study.

Firstly, we deal an initial surface of the form $y(x)=h_{0}-k x^{\alpha}$ where $\alpha=1 / 2$ and search its surface morphology and the height change in time for $g^{\prime}=0$ and $g^{\prime}=1$ respectively. During

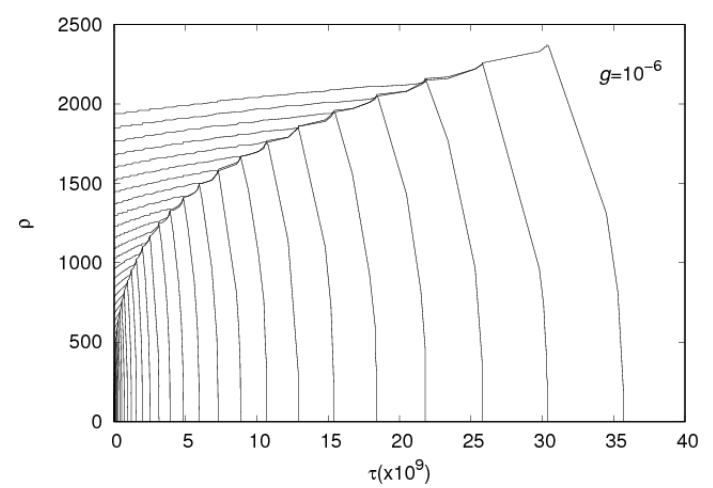

Figure 3. Time evolutions of the step radii as a function of time for $g=10^{-6}$ in the case of $g^{\prime}=0$ investigation we took the initial heights of surfaces and the intersection point $\left(x_{0}\right)$ of the initial surface on the $x$ axis as 50 and 2500 in units lattice constant respectively while we changed the value of $g$ from $10^{-6}$ to $10^{-3}$. In the case of only repulsive interactions between steps, the surfaces evolved properly, i.e. step bunching has not been formed on the surface. The variation of step radii as a function of time is shown in Figure 3 for the value of $g=10^{-6}$. In the figure each line represents the evolution of the radius of one step. While the innermost step disappears the other steps absorb the atoms emitted by the disappeared step and expand. This event continues till few steps remain on the structure. We saw that the variations of the height of the surfaces as a function of time were the same for all $g$ values. These are shown in Figure 4.

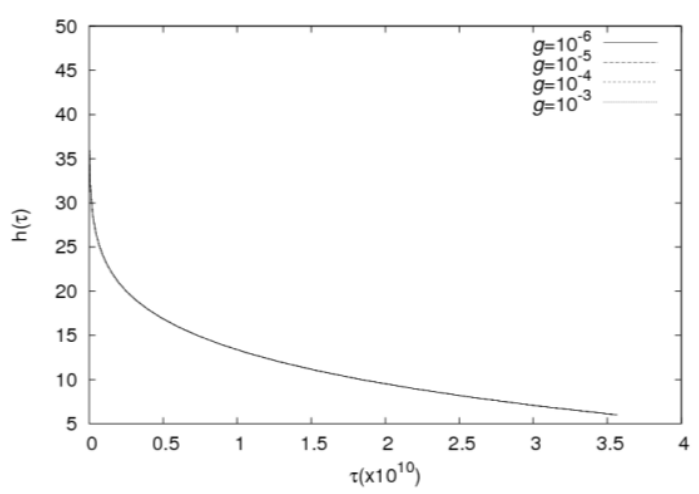

Figure 4. The variations of the heights of the surfaces for different values of $g$ as a function of time. The surfaces showed the same behavior for all $g$ values.

We took into account the attractive interaction in addition to repulsive interaction to see the effect of this kind of interaction on the surface's morphology and the variation of the surface's height. So we assumed the value of $g^{\prime}$ as 1 . The other parameters were supposed the same as used before like $h_{0}, x_{0}$ and $g$. The step bunching has not been occurred on the surface for $g=10^{-6}$ and $10^{-5}$ values. The variation of step radii and the evolution of the height as a function of time are shown in Figure 5 for the value of $g=10^{-5}$. 

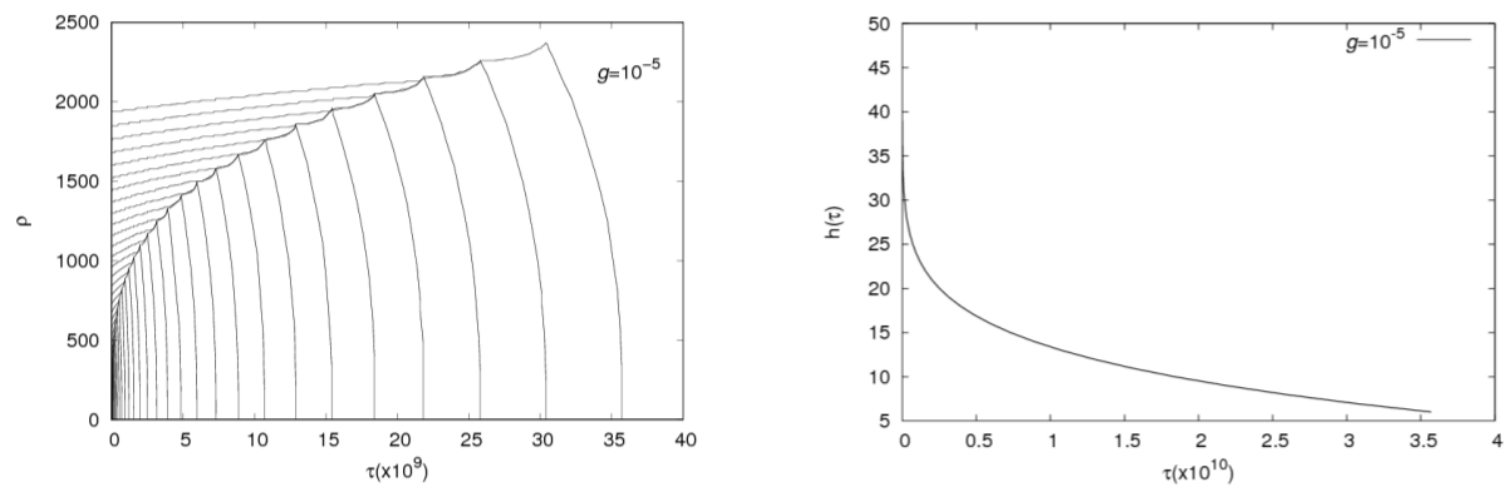

Figure 5. Time evolutions of the step radii and the evolution of the height of the surface as a function of time for $g=10^{-5}$ in the case of $g^{\prime}=1$.

When we increased $g$ value to $10^{-4}$, the surface started to become unstable and we saw that step bunching has been occurred on the surface and the variation of surface's height became irregular (Figure 6). The surface has been unstable in consequence of the step bunchings. It has been determined that the scale of step bunching occurred on the surface increased by increasing $g$ value from $10^{-4}$ to $10^{-3}$. This can be seen from in Figure 7 . Double, triple and more steps start to form in a bunch. When a bunch arrive to the top of the surface, steps in bunch disappear from the surface quickly. When $g$ value is small, the number of steps in a bunch is also small and it increases as $g$

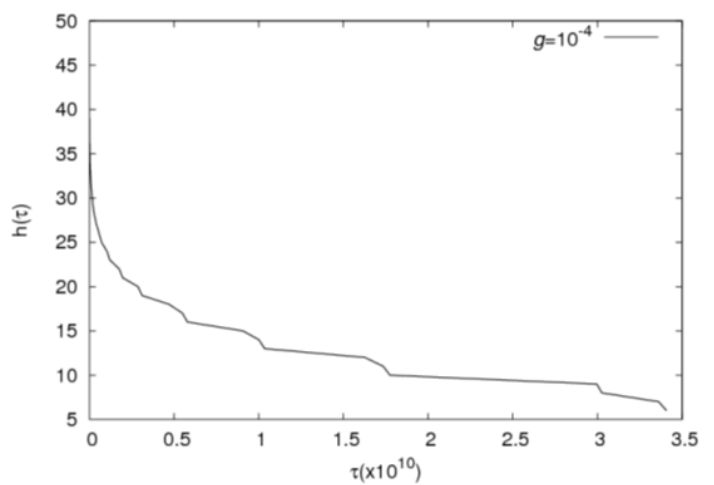
value increases.
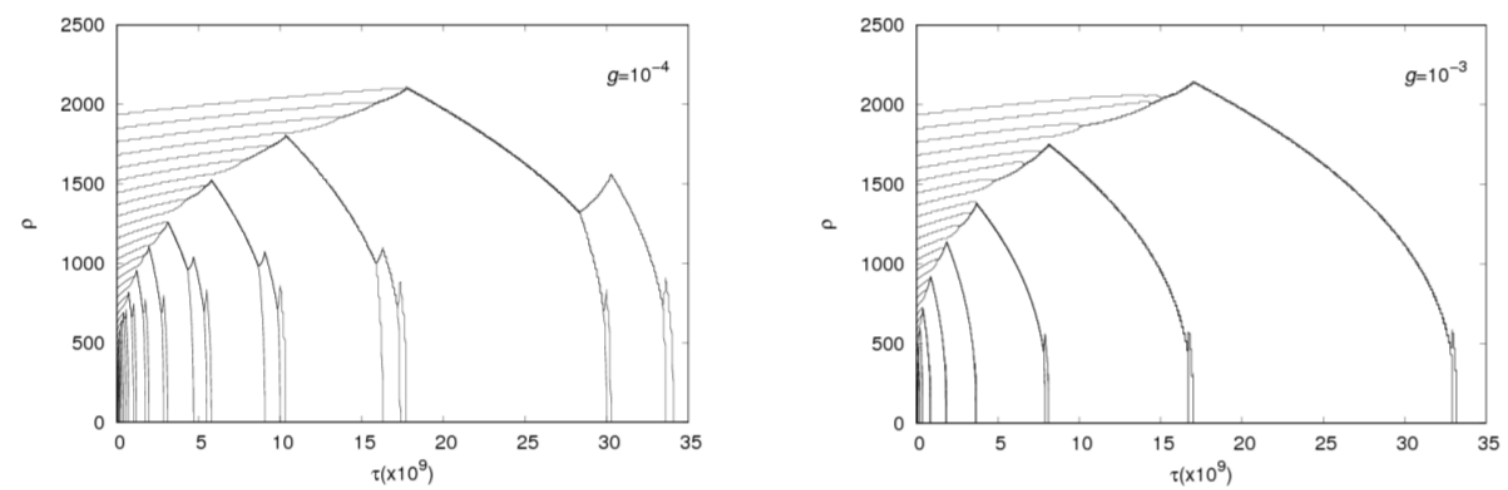

Figure 7. Time evolutions of the step radii for $g=10^{-4}$ and $10^{-3}$ under the effects of attractive and repulsive interactions. When the value of $g$ is small, the number of steps in a bunch is also small and it increases as the value of $g$ increases.

When we repeated the same investigation with the same parameters for $\alpha=1 / 3$ we determined that the step bunching has not been occurred on the surface for all $g$ values in the case of only repulsive interactions between steps similar to cases in $\alpha=$ $1 / 2$. The evolutions of all surfaces were regular (The heights' changes of the surfaces in time are similar to Figure 4). For $g^{\prime}=1$, while the surfaces evolved properly for $g=10^{-6}$ and $g=10^{-5}$ values, the step bunches has been seen on the surface by increasing the value of $g$ to $10^{-4}$. When we took $g$ value as $10^{-3}$, step bunchings occurred on the surface have been increased. In addition we have derived a parameter space for the bunching- 
no bunching regions by using $g$ and $g^{\prime}$. We have determined that while $g^{\prime}$ increases, the value of $g$ must be decreased for bunching not to occur on the surface. Different pairs of these parameters are possible to be either the bunching or no bunching

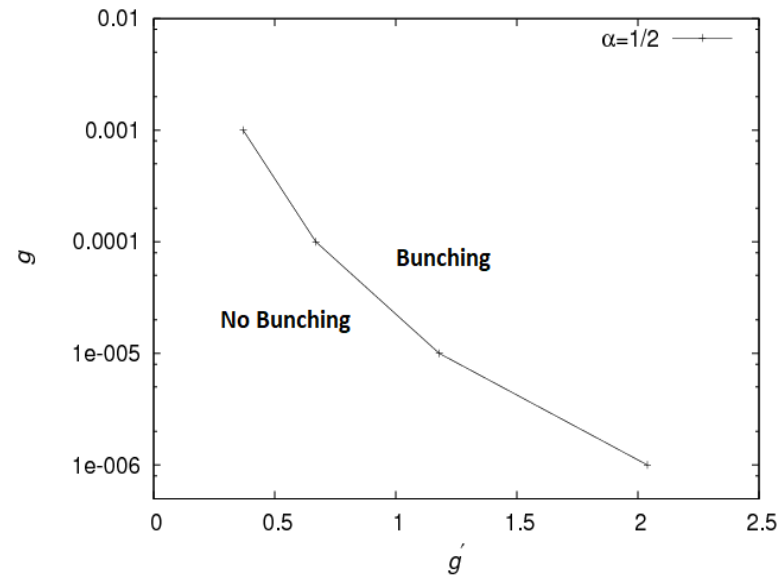

region. The parameter space of bunching and no bunching regions for $\alpha=1 / 2$ and the comparison of the parameter spaces of $\alpha=1 / 2$ and $\alpha=1 / 3$ are shown in Figure 8.

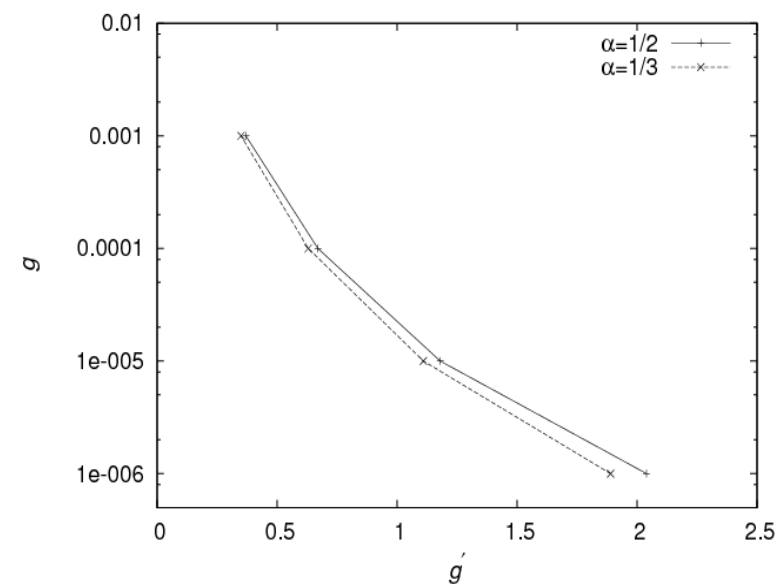

Figure 8. The parameter space of bunching and no bunching regions for $\alpha=1 / 2$ is on left side of the figure. The comparison of the parameter spaces for $\alpha=1 / 2$ and $\alpha=1 / 3$ is right side. While the value of the $\alpha$ (which is less than 1 ) decreases, the areas of the bunching and no bunching regions increases and decreases respectively.

In the second part of the study, we took the values of $\alpha$ in the $y(x)$ function as 2 and 3 to analyze the surface morphology and the evolution of the surface height for $g^{\prime}=0$ and $g^{\prime}=1$ respectively. While we changed the value of $g$ from $10^{-6}$ to $10^{-3}$, we chose the initial heights of surface, $h_{0}=$ 50 , and the intersection point of the surface on the $x$ axis, $x_{0}=2500$ again. For $g^{\prime}=0$ (only repulsive interactions between steps), no bunchings occurred on the surface during evolutions for all values of $g$, so the evolutions of the surfaces' heights were regular and similar to Figure 4 for every two cases of $\alpha=2$ and $\alpha=3$. In the case of attractive and repulsive interactions between steps $\left(g^{\prime}=1\right)$ for $\alpha=2$ and $\alpha=3$, the step bunches has not been seen on the surface for $g=$ $10^{-6}$. The height changes of these surfaces were clean shown in Figure 9.

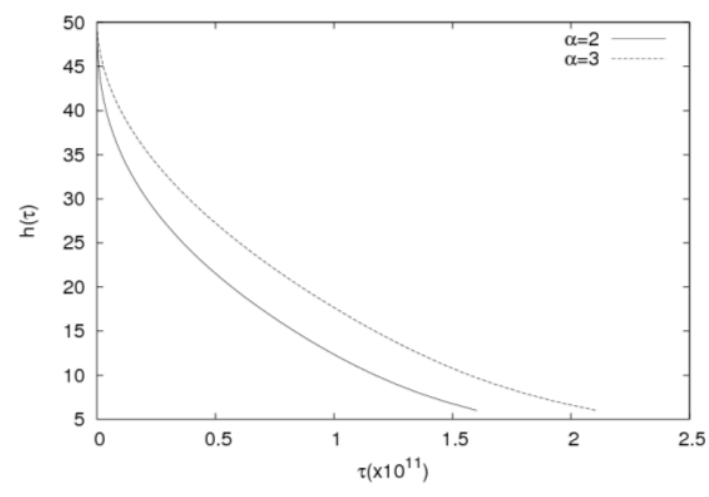

Figure 9. The step bunches has not been seen on the surface for $g=10^{-6}$ for the values of $\alpha=2,3$, when there were the attractive and the repulsive interactions between steps on the surface. The height changes of dealt surfaces are clean shown as above.

When we increased $g$ value to $10^{-5}, 10^{-4}$ and $10^{-3}$ for $\alpha=2$ and 3 respectively, we found that step bunching has started to form for $10^{-5}$ and the numbers of the step bunches and the steps in bunches have been increased as $g$ value increased to $10^{-4}$ and $10^{-3}$ respectively. Therefore the variation curve of surface's height became irregular. The evolutions of heights and the surface morphologies for $\alpha=2$ can be seen from Figure 10. 

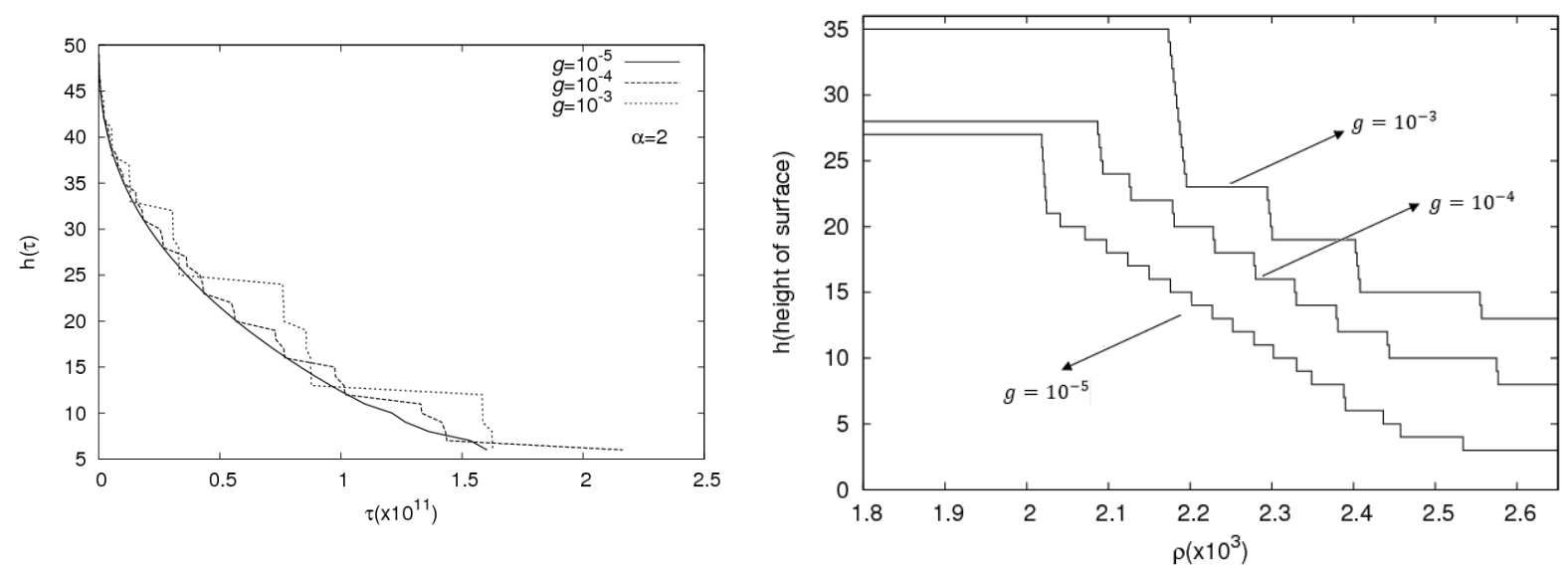

Figure 10. The variations of heights of the surface which has $\alpha=2$ for $g=10^{-5}, 10^{-4}, 10^{-3}$. The step bunches which contain more steps occur on the surface with increasing the value of $g$.

Besides the comparison of the parameter spaces of bunching and no bunching regions for $=2$ and $\alpha=3$ is given in Figure 11 below. In the figure, the regions which are under the curves indicate no bunching regions and the regions over the curves are the bunching regions of the graph. When Figure 11 is analyzed, it is seen that while the value of $\alpha$ (which is greater than 1) in the $y(x)=h_{0}-k x^{\alpha}$ expression is increasing, the area of the bunching region expands.

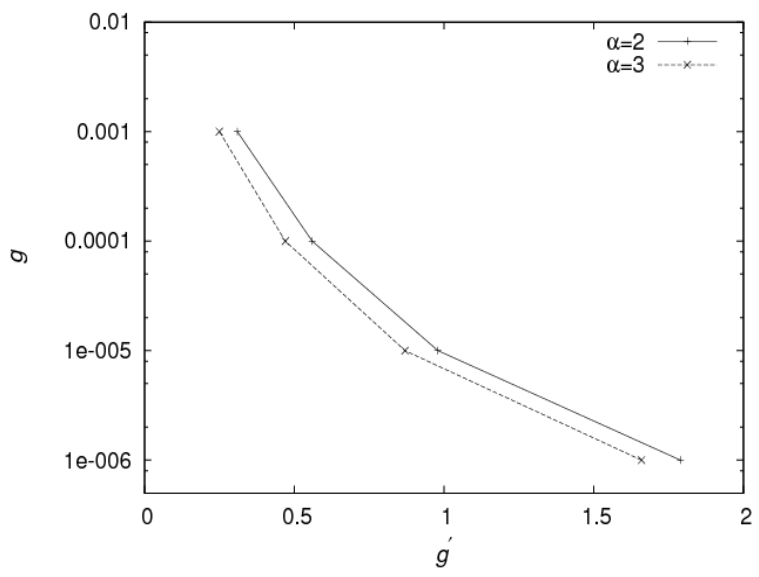

Figure 11. The parameter space of bunching and no bunching regions for $=2$ and $\alpha=3$. While the value of the $\alpha$ (which is greater than 1) increases, the areas of the bunching and no bunching regions increases and decreases respectively.

\section{CONCLUSION}

We have examined the evolutions of initial surfaces which have an edge structure coincide with an envelope function of the form $y(x)=h_{0}-$ $k x^{\alpha}$ in DL regime. The surfaces consist of concentric circular monoatomic steps separated by terraces. We have solved the diffusion equation on each terrace by using polar coordinates and the velocity of each step is written by assuming the line tension of steps, the repulsive and attractive interactions between neighboring steps. For the dealt surfaces $\left(\alpha=\frac{1}{3}, \frac{1}{2}, 2,3\right)$, we determined that the step bunchings have not been occurred on the surfaces for all $g$ values in the case of only repulsive interactions between steps $\left(g^{\prime}=0\right)$. All surfaces showed the same behavior in this case. When there were repulsive and attractive interactions between steps $\left(g^{\prime}=1\right)$, we identified the cases in which conditions step bunchings occurred and didn't occur for all dealt surfaces. After we identified these cases, we achieved the parameter spaces of bunching and no bunching regions for all $\alpha$ values. 


\section{REFERENCES}

[1]. W. K. Burton, N. Cabrera, F. C. Frank, The Growth of Crystals and the Equilibrium Structure of Their Surfaces, Philos. Trans.R. Soc. London A 243 (1951) 299.

[2]. J. Villain, Healing of a Rough Surface at Low Temperature, Europhys. Lett. 2 (1986) 532.

[3]. M. Uwaha, Relaxation of Crystal Shapes Caused by Step Motion, J. Phys. Soc. Jpn 57 (1988) 1681.

[4]. N. Israeli, D. Kandel, Profile Scaling in Decay of Nanostructures, Phys. Rev. B 80 (1998) 3300.

[5]. N. Israeli, D. Kandel, Profile of Decaying Crystalline Cone, Phys. Rev. B 60 (1999) 5946.

[6]. M. Uwaha, K. Watanabe, Decay of an Island on a Facet via Surface Diffusion, J. Phys. Soc. Jpn 69 (2000) 497.

[7]. A. Ichimiya, K. Hayashi, E.D. Williams, T.L. Einstein, M. Uwaha, K. Watanabe, Decay of Silicon Mounds: Scaling Laws and Description with Continuum Step Parameters, Appl. Surf. Sci. 175-176 (2001) 33.

[8]. S. Kodambaka, N. Israeli, J. Bareno, W. Swiech, K.Ohmori, I. Petrov, J.E. Greene, Low-Energy Electron Microscopy Studies of Interlayer Mass Transport Kinetics on TiN(1 11 1), Surf. Sci. 560 (2004) 53.

[9]. M. Esen, A.T. Tüzemen, M. Ozdemir, Equilibration of a Cone: KMC Simulation Results, European Physical Journal B 85 (2012) 117.

[10]. A. F. Andreev, A.Y. Kosevich, Capillary Phenomena in the Theory of Elasticity, Sov. Phys. JETP 54 (1981) 761.

[11]. E. M. Pearson, T. Halicioglu, W. A. Tiller, Long-range Ledge-ledge Interactions on Si(l 11 1) Surfaces: I. No Kinks or Surface Point Defects, Surf. Sci., 184, (1987) 401.

[12]. A. F. Andreev, Faceting Phase Transitions of Crystals, Sov. Phys. JETP 53 (1981) 1063.

[13]. E. E. Gruber, W.W. Mullins, On the Theory of Anisotropy of Crystalline Surface Tension, J. Chem. Solids 28 (1967) 875.
[14]. J. J. Saenz, N. Garcia, Classical Critical Behaviour in Crystal Surfaces Near Smooth and Sharp Edges, Surf. Sci., 155, (1985) 24.

[15]. J. C. Heyraud, J. J. Metois, Establishment of the Equilibrium Shape of Metal Crystallites on a Foreign Substrate: Gold on Graphite, J. Cryst. Growth, 50, (1980) 571.

[16]. J. J. Metois, J. C. Heyraud, Analysis of the Critical Behaviour of Curved Regions in Equilibrium Shapes of in Crystals, Surf. Sci., 180, (1987) 647.

[17]. J. Frohn, M. Giesen, M. Poensgen, J. F. Wolf, H. Ibach, Attractive Interaction Between Steps, Phys. Rev. Lett., 67, (1991), 3543.

[18]. K. Sudoh, H. Iwasaki, E. D. Williams, Facet Growth Due to Attractive Step-Step Interactions on Vicinal Si(1 13 ), Surf. Sci., 452 (2000) 287-292.

[19]. V. B. Shenoy, S. Zhang, W. F. Saam, Step Bunching Transitions on Vicinal Surfaces with Attractive Step Interactions, Surf. Sci., 467 (2000) 58-84.

[20]. W. Kossel, Zur Theorie des Kristallwachstums, Nachr. Ges. Wiss. Göttingen, Math-Phys. Kl., (1927) 135.

[21]. I. N. Stranski, Zur Theorie des Kristallwachstums, Z. Phys. Chem. (Leipzig), 136, (1928) 259.

[22]. M. Ozdemir, The Morphology of Crystalline Surfaces in the Presence of Attractive Step Interactions, J. Phys.: Condens. Matter 11, (1999) 1915.

[23]. M. Ozdemir, Epitaxial Growth to NonPlanar Substrates by Step-Flow, App. Surf. Sci., 152 (1999) 200-212.

[24]. A. T. Tüzemen, M. Esen, M. Ozdemir, Scaling Properties of Equilibrating Semiconductor Mounds of Various Initial Shapes, J. Crystal Growth, 470 (2017) 9498.

[25]. S. Tanaka, N. C. Bartelt, C. C. Umbach, R. M. Tromp, J. M. Blakely, Step Permeability and the Relaxation of Biperiodic Gratings on Si(0 0 1), Phys. Rev. Lett. 78 (1997) 3342.

[26]. H. C. Jeong, E. D. Williams, Steps on Surfaces: Experiment and Theory, Surface Science Reports 34 (1999) 171-294. 